\title{
The Pragmatic and the Dogmatic Spirit in Physics
}

\section{By Prof. J. Stark, President of the Physikalisch-Technischen Reichanstalt, Berlin-Charlottenburg}

$\mathrm{T}$ HE aim of physical science is the investigation and formulation of the laws which govern the properties and processes observed with objects of inanimate Nature. These inherent laws are independent of human existence, action, and thought, and are the same all over the world. For this reason, the object of physical science is international. But the manner in which physical research is carried out and described depends on the spirit and character of the men of science engaged upon it, and this spirit and character differ individually, as do men, nations and races.

When in what follows I speak of two principal types of mentality in physics, my observations are founded on experience. I have inquired into the mental characteristics that have led the great physicists of the past to their discoveries, and in the course of the forty years of my scientific life I have observed very many more or less successful contemporary physicists and authors of theories and of books, in an endeavour to discern the mainspring of their work. On the basis of this wide experience $I$ have come to recognize that there are two main types of mental attitude among workers in the field of physics.

The pragmatic spirit, from which have sprung the creations of successful discoverers both past and present, is directed towards reality ; its aim is to ascertain the laws governing already known phenomena and to discover new phenomena and bodies as yet unknown. Even before they tackle a particular problem, physicists of this school of thought have acquired a certain feeling of the reality of the phenomena to be investigated, by giving careful attention to all previously ascertained facts connected with their problem. On the basis of this feeling they form a conception as to what the body or process to be investigated may be like in reality. For them, however, such a conception is solely the means to the end of devising experimental arrangements for the empirical formulation of their question to reality itself. If the observations made with the apparatus chosen do not confirm the initial conception, as very frequently happens, they reject it without hesitation and seek stimulation from experience for a new conception for the purpose of new experiments. Their final goal is always to establish reality, whether they gain new knowledge or are led to obscure and still unexplored features of the phenomena investigated. The mathematically formulated theory is to physicists of the pragmatic spirit not an end in itself, but solely a method for the purpose either of presenting the knowledge gained from experience in a quantitative manner and as briefly and simply as possible, or of deriving mathematically for special cases results which follow from general laws obtained from experiment.

The physicist of the dogmatic school operates in quite a different manner in the field of physics. He starts out from ideas that have arisen primarily in his own brain, or from arbitrary definitions of relationships between symbols to which a general and so also a physical significance can be ascribed. By logical and mathematical operations he combines them and so derives results in the form of mathematical formulæ. He then seeks to give these a physical meaning by applying them to the results of experience. In so far as they are found to be in accord with experience, he underlines this agreement with the greatest of emphasis, and makes it appear as though the results of experience have been established and have gained scientific importance only by virtue of his theory. If there are any experimental results available that are not embraced by this theory or which stand in contradiction to it, he doubts their validity or considers them so unimportant that he does not deign to mention them. Dogmatic physicists further present things as though their theories and formulæ exhaustively covered the whole range of phenomena treated by them; they can see no further problems in this field, and thought and inquiry are ice-bound in their formulæ.

The aim of the pragmatic spirit is reality, and his way to this goal is appropriate and careful observation; the goal of the dogmatic spirit is the dogmatic formula, and his way is one of logical mathematical construction. For the pragmatic spirit physical research is a process of evolution from what has been established to new experimental knowledge ; for him there is no such thing as classical physics or modern physics, but only physics. For the dogmatic spirit physics is a field for his logical formalistic activity towards revolution against existing principles and towards the accomplishment of general acceptance of his theories or, indeed, of his new 'world-picture' (Weltbild). The pragmatic spirit advances 
continuously to new discoveries and new knowledge ; the dogmatic spirit leads to the crippling of experimental research, and to a literature which is as effusive as it is unfruitful and tedious, intrinsically akin to the theological dogmatism of the Middle Ages, which was opposed to the introduction of pragmatic natural science.

The researches of Lenard and of Rutherford present us with obvious recent examples of the manner in which the pragmatic spirit works in physics. By his experimental investigations on cathode rays, Lenard paved the way for the greatest discovery of the last fifty years, that of the electron, and furthermore, in the photo-electric effect, he revealed by careful measurements the connexion between the electron and light. From his intuitive sense of reality and by convincing experiments and measurements, Rutherford derived our knowledge of the radioactive transforma. tion of chemical atoms and of their nuclear structure, knowledge which could never have been derived by dogmatic methods. The relativistic theories of Einstein, which are based on an arbitrary definition of space and time co-ordinates or their differentials, constitute an equally obvious example of a product of the dogmatic spirit. Another example of this kind is the wave-mechanical theory of Schrödinger. By an amazing feat of physico-mathematical acrobatics he obtains as a final result first a differential equation. He then asks what sort of physical significance the function that occurs in his equation may have, and for this he makes a suggestion, according to which the electron is arbitrarily smeared in a large spatial region round about the atom. In characteristic fashion, however, other dogmatic physicists (Born, Jordan, Heisenberg, Sommerfeld) give to the Schrödinger function another dogmatic significance, contrary to fundamental laws of experience. They make the electron dance round the atom in an irregular manner, and allow it to act externally as though it were simultaneously present at every point round about the atom with a charge corresponding to the statistical duration of its sojourn at each point.

There is still another important difference between the pragmatist and the dogmatist in physics, which has to do more with the characters of these two types. The physicist of the pragmatic spirit does not conduct propaganda for the results of his research in order to gain authority and influence; he finds his satisfaction in obtaining new knowledge and trusts that it will receive recognition from the expert as a representation of reality, and that it will serve as a step towards new advances. How different are the protagonists of the dogmatio spirit! They do not first wait for at least five years to see whether their revolutionary fashioned theories may perhaps prove to be inadequate or erroneous when examined in the light of experience. On the contrary, almost before they have been published, a flood of propaganda for them is started by articles in journals and newspapers, by text-books and by lecture tours, if possible right round the world. So far as I am aware, Rutherford never undertook lecture tours to make known the results of his researches. Of Lenard I know that he detested speaking about his researches before a wide public, and that he only twice took part in the German Congress of Natural Science (Naturforscherversammlung). On the other hand, older physicists will probably still remember with what pertinacity propaganda was carried on all over the world and before the widest public for Einstein's theories of relativity. Matters have not been quite so bad with the newer dog. matic theories which have been advertised under such terms as quantum theories, quantum mechanics, and so on; nevertheless, for the purpose of propaganda on their behalf, innumerable lectures have been held throughout the world, and very many text-books have been written about them.

In so far as the task of physics is the investigation of bodies and of laws concerning the reality of Nature, only the pragmatic attitude of men of science is qualified to solve them, and hence also alone entitled to do so. When the dogmatic spirit does not confine itself to theology and sociology, but also chooses physics as an arena for its intellectual gymnastics, one might tolerate this, but only under the condition that physical research of the pragmatic school of thought does not suffer in consequence. But for about three decades this condition has not been satisfied, at any rate not in Germany, where during this time the representatives of the dogmatic spirit have gained a dominating influence. By their collective action and their connexion with earlier Ministries they were able to acquire numerous chairs in physics, and above all in theoretical physics. In consequence of this, and because of the lively propaganda for modern dogmatic theories, academic youth was predominantly educated in the scientific ideal of the dogmatic spirit. Not men like Lenard and Rutherford, but Einstein and his dogmatic imitators were held up to them as models for scientific thought and work. I have taken the field against the dogmatic spirit in Germany because I have been able to observe repeatedly its crippling and damaging effect on the development of physical research in this country. In this conflict I have also directed my efforts against the damaging influence of Jews in German science, because I regard them as the chief exponents and propagandists of the dogmatic spirit. 
This reference brings me to the national aspects of the mental outlook of men of science in research. It can be adduced from the history of physics that the founders of research in physics, and the great discoverers from Galileo and Newton to the physical pioneers of our own time, were almost exclusively Aryans, predominantly of the Nordic race. From this we may conclude that the predisposition towards pragmatic thinking occurs most frequently in men of the Nordic race. If we examine the originators, representatives and propagandists of modern dogmatic theories, we find amongst them a preponderance of men of Jewish descent. If we remember, in addition, that Jews played a decisive part in the foundation of theological dogmatism, and that the authors and propagandists of Marxian and communistic dogmas are for the most part Jews, we must establish and recognize the fact that the natural inclination to dogmatic thought appears with especial frequency in people of Jewish origin.

In establishing these facts, of course, I do not maintain that there are no Aryan men of science who are actively engaged in the dogmatic spirit in the realm of science ; nor do I maintain that Jews cannot produce valuable experimental work carried out in the pragmatic spirit. I wish solely to make a statement on the frequency of occurrence of the natural tendency to pragmatic or to dogmatic ways of thinking. It must also be taken into consideration that, by training and practice, Aryans can become accustomed to the dogmatic and Jews to the pragmatic habits of thought. I acknowledge scientific achievement in new discoveries irrespective of the nationality of the discoverer, and I combat the harmful influence of the dogmatic spirit in physics whenever I encounter it in my scientific work, and regardless of whether the culprit is a Jew or not. Moreover, I have been engaged in this fight not only since 1933, for as long ago as the year $1922 \mathrm{I}$ denounced in the strongest terms the formalism and dogmatism in German physics in one of my publications entitled : "The Present Crisis in German Physics".

\section{Problems in the Oceanography of the North Atlantic}

\section{By C. O’D. Iselin, Woods Hole Oceanographic Institution, Woods Hole, Mass.}

PRogr ROGRESS in our understanding of ocean circulation has generally been even slower than in some of the other branches of oceanography, in spite of the fact that in nearly every marine problem, both biological and physical, the current system plays a basic part.

At first the study of ocean currents was held back by the lack of accurate and convenient instruments. In more recent times, the expense of securing the observations has delayed the accumulation of adequate subsurface data on the distribution of temperature and salinity. If this were known in sufficient detail, it would probably not be a difficult task to settle several of the main problems which now confront physical oceanographers.

In particular, physical oceanographers have been unable to supply the climatologists and fisheries experts with the much-needed data on the variability of oceanic currents. Do ocean currents transport about the same amount of heat year after year, and are they, therefore, unimportant from the point of view of long-range weather forecasting? It is now known that changes in oceanic circulation have, on occasions, affected the fisheries of Great Britain; but it is not yet known if fluctuations in the strength of the Gulf Stream off the American coast bear any relation to fluctuations in the circulation of the water masses off the European coast. ${ }^{1}$ Not only are such questions of considerable economic importance in some parts of the world, but also if the answers were known, it would be much easier to secure the necessary financial support to develop fully the science of oceanography.

For these reasons it is very encouraging that arrangements have been made during the past year for a co-operative programme of broad scope. The programme is to be undertaken jointly by the Bermuda Oceanographical Committee of the Royal Society and by the Woods Hole Oceanographic Institution. The Royal Society has obtained a generous grant from the British Government for the promotion of the scheme, and the Bermuda Biological Station is being developed as a base for the oceanographic work. The plan, which will shortly be in actual operation, involves the cooperation of the American oceanographers with the now increased staff of the Bermuda Biological Station; and the British grant, which covers a five-year period, also provides the Station with a much-needed research vessel.

The programme which has been suggested and on which work has already begun (June 1937) is essentially a continuation of modern oceanographic development, but it is hoped that it will be 